\title{
Compensation for research injuries: Thoughts from a human research ethics committee chair
}

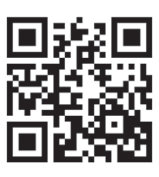

The Venter case for research injury compensation following a clinical trial ${ }^{[1]}$ is the first I am aware of in South African (SA) courts during my service on research ethics committees (RECs) since 1974. Moreover, of the several thousand clinical trials approved in the past 40 years by the Human Research Ethics Committee (Medical) at the University of the Witwatersrand, there has been only one claim for compensation for a research injury of an enduring nature. In this case, about a decade ago, a participant in a clinical trial developed idiopathic hypertension; the sponsor agreed that this was trial related, and has provided long-term care for the hypertension without a need to approach the courts.

With this limited knowledge I did an online search for court cases for compensation due to research injury, particularly during clinical trials under the Association of the British Pharmaceutical Industry (ABPI) guidelines. ${ }^{[2]}$ My search was disappointing because the outcome was swamped with claims associated with medical 'negligence'; linkage to clinical trials and the ABPI guidelines was hidden, if present at all. However, one case in the UK involving the ABPI guidelines (Wyle vs Grosset Greater Glasgow Health Board 2011 CSOH 89) was mentioned in the Venter judgement. This limited compensation to 'appropriate medical treatment. ${ }^{\text {[3] }}$

Section 10 of the Declaration of Helsinki $2013^{[4]}$ states that 'Appropriate compensation and treatment for subjects who are harmed as a result of participating in research must be ensured.' Under this principle, what types of compensation are available in different countries? I found so much variation between and within countries that it would be impossible to discuss this in an editorial, or even a full article. However, a recent report from the US Presidential Commission for the Study of Bioethical Issues, ${ }^{[5]}$ which has two summary appendices listing compensation methods in four US federal agencies and 45 'international and transnational requirements', is useful. 
A US federal agency that supports much research in SA is the National Institutes of Health (NIH). For in-house research, 'the Clinical Centre of the NIH will provide short-term medical care ... In general, no long-term medical care or financial compensation for research-related injuries will be provided ... ${ }^{\left[{ }^{[j]}\right.}$ Those serving on RECs in SA will be familiar with the absence of research injury compensation in NIH-sponsored research, something challenged by SA REC chairs in 2006. ${ }^{[6]}$ In fact, little has changed since 20 years ago, when it was reported that in the USA 'there is no comprehensive program to cover injuries resulting from privately and publically funded research?. ${ }^{[]]}$

Is alteration in research injury compensation policy also slow in the USA outside the federal system? Resnik et al. ${ }^{[8]}$ looked for change in compensation policy over a decade by secondary analysis of data sets from surveys in US research institutions in $2002(N=127)$ and $2012(N=169)$. There was minimal change in compensation policies, the percentage without compensation (including treatment) being $56.1 \%$ in 2000 and $51.2 \%$ in 2012 . Importantly, Resnik et al. ${ }^{[8]}$ noted that a 'significant percentage of policies contain language that can reasonably interpreted as waiving, or appearing to waive, legal rights'.

Examination of the summaries of the 45 international requirements listed in the Commission's report ${ }^{[5]}$ shows that $62 \%$ require insurance, $36 \%$ want treatment to be provided for a research injury, $20 \%$ offer economic compensation, $13 \%$ indemnify researchers and sponsors, $11 \%$ have vague statements that compensation is needed, and only $1 \%$ offer both treatment and economic compensation as stated by the Declaration of Helsinki. ${ }^{[5]}$ None of the requirement summaries mention quantum of compensation, which is not surprising. It is a complex and difficult matter, since variables to be considered include who should be compensated, for what (will known complications be excluded?), by whom, at what quantum, and who will decide. For the latter, Denmark, Finland and New Zealand cite general laws and government bodies dealing with compensation that would be used. ${ }^{[5]}$ Collaboration between legal experts, bioethicists, clinicians and insurers will be necessary.

The current Presidential Commission ${ }^{[5]}$ noted that 'Almost all other developed nations have instituted policies to require treatment, or compensation for treatment, for injuries suffered by research subjects.' The Commission acknowledged past recommendations by presidentially appointed bioethics commissions and other groups for the USA to establish federal compensation policies, and the lack of progress in fulfilling this. In the absence of these policies, local researchers in Africa rely on insurance during NIH-sponsored HIV/AIDS clinical trials. ${ }^{[9]}$ The current Commission report advised a cautious, systematic approach towards establishment of policies. ${ }^{[5]}$ There is no reason to believe that change of compensation requirements in SA would not follow a similar slow course.
Strode and Singh ${ }^{[1]}$ believe that 'RECs ... protect the rights and welfare of research participants by carefully reviewing compensation clauses in informed-consent documents.' I agree. Since change in compensation policy in our country is likely to take time to fulfil the requirements of the Declaration of Helsinki, ${ }^{[4]}$ what should RECs do now? My view is that potential participants need to have a better understanding of the ABPI-based compensation policy.

What happens at present is that late in an information sheet, perhaps in the last few of many pages, there is a paragraph or two that describes compensation available from the sponsor, under certain conditions including the ABPI guidelines, should there be a trial-related injury. Included is a statement that 'this does not affect the right of a participant to pursue a legal remedy in respect of injury alleged to have been suffered as a result of participation. ${ }^{[10]}$ This is surely similar to the confusing language found in the USA by Resnik et al. ${ }^{[8]}$ What some sponsors have been saying in recent times seems clearer to me, namely that a participant's right to claim for compensation is not affected, but negligence must be proven.

Whatever information on compensation is provided to a potential participant in a clinical trial information sheet, my belief is that it should be on a separate page requiring a signature and preferably combined with questioning to ensure that the potential participant understands it. Perhaps this should be in the front of an informed consent form, which would certainly help RECs reviewing an application, as well as the potential participant.

\section{Peter Cleaton-Jones}

Chair, Human Research Ethics Committee (Medical),

University of the Witwatersrand, Johannesburg, South Africa

Corresponding author: P Cleaton-Jones (peter.cleaton-jones@wits.ac.za)

1. Strode A, Singh PP. Compensation for research-related harm: The implications of Venter $v$ Roch Products (Pty) Limited and Others for research ethics committees. S Afr Med J 2014;104(11):759-761. [http://dx.doi.org/10.7196/SAM].8596]

2. Clinical Trial Compensation Guidelines. The Association of the British Pharmaceutical Industry. 1994 http://www.abpi.org.uk/our-work/library/guidelines/Pages/ct-compensation.aspx (accessed 18 August 2014)

3. Venter vs Roche Products (Pty) Limited and Others (case no. 12285/08).

4. Declaration of Helsinki 2013. http://www.wma.net/en/30publications/10policies/b3/ (accessed 7 January 2014).

5. Presidential Commission for the Study of Bioethical Issues. Moral Science Protecting Participants in Human Subjects Research. Updated version June 2012. http://www.bioethics.gov (accessed 21 August 2014).

6. Cleaton-Jones P, Wassenaar D, Hammann E, et al. Research injury in clinical trials in South Africa. Lancet 2006;367(9509):458-459. [http://dx.doi.org/10.1016/S0140-6736(06)68158-0]

7. Institute of Medicine. Women and Health Research: Ethical and Legal Issues of Including Women in Clinical Studies, Vol. 1. Washington, DC: National Academies Press, 1994:243. http://wwwnapedu/ Clinical Studies, Vol. 1. Washington, DC: National Academies Press,
openbook.php\%record id $=2304$ \&page $=243$ (accessed 22 August 2014)

8. Resnik DB, Parasidis E, Carroll K, Evans JM, Pike ER, Kissling GE. Research-related injury Resnik DB, Parasidis E, Carroll K, Evans JM, Pike ER, Kissling GE. Research-related injury
compensation policies of US research institutions. IRB 2014:36(1):12-19. compensation policies of US research instituit
pubmed/24649739 (accessed 18 August 2014).

9. Mamotte N, Wassenaar D, Singh N. compensation for research-related injury in NIH-sponsored HIV/AIDS clinical trials in Africa. J Empir Res Hum Res Ethics 2013;8(1):45-54. [http://dx.doi.org/10.1525/jer.20138.145] 10. Department of Health Guidelines Res Ethics 2013;8(1):45-54. [http://dx.doi.org/10.1525/jer.2013.8.1.45] Peparticipants in South Africa. 2nd ed. Pretoria: Department of Health, 2006:43.
Partical Trials with Human

S Afr Med J 2014;104(11):755-756. DOI:10.7196/SAMJ.8939 